AD/RHIC-68

\author{
R H I C P R O J E C T \\ Brookhaven National Laboratory \\ Associated Universities, Inc. \\ Upton, NY 11973
}

\title{
The Heavy Ion Stripping Foil Requirements between AGS and RHIC
}

\author{
M.J. Rhoades-Brown
}

March 1990 


\title{
The Heavy Ion Stripping Foil Requirements \\ between AGS and RHIC
}

\author{
M. J. Rhoades-Brown
}

\section{Introduction}

The very heavy ion injection scenario of $\mathrm{RHIC},{ }^{1}$ calls for a stripping foil to be located at the transfer line between the AGS and RHIC. This foil has to remove the two remaining $\mathrm{K}$-shell electrons from the very heavy ions, before injection into RHIC.

In this paper we calculate the characteristics of this foil, including the expected fraction of fully ionized heavy ions as a function of foil thickness, the growth in the transverse emittance of the beam after traversing the foil, and the effect of the foil on the energy spread of the beam. Two beams $\left({ }^{197} \mathrm{Au}^{77+}\right.$ and $\left.{ }^{238} \mathrm{U}^{90+}\right)$ will be investigated together with three types of stripping foils $\left({ }^{27} \mathrm{Al},{ }^{63} \mathrm{Cu},{ }^{197} \mathrm{Au}\right)$.

It is assumed ${ }^{2}$ that following acceleration in the AGS, the ${ }^{197} \mathrm{Au}^{77+}$ and ${ }^{238} \mathrm{U}^{90+}$ beams have a kinetic energy $E$ of $10.4 \mathrm{GeV} / \mathrm{u}(\gamma \sim 12.0)$ and a maximum energy spread $\sigma_{\mathrm{E}}^{\max }=E \times 10^{-4}=1.0 \mathrm{MeV} / \mathrm{u}$.

\section{The Stripping Process}

The problem is to study the charge distribution of ions moving with relativistic velocities through target foils. In these relativistic collisions, capture processes are relatively unimportant compared to ionization ones. ${ }^{3}$ Denoting the cross section for changing the number of electrons on the projectile from $n_{i}$ to $n_{f}\left(=n_{i}-1\right)$ by $\sigma\left(n_{i}, n_{f}\right)$, the rate equation for the charge--state fractions $Y_{n}(T)$, at a thickness $T$ (in atoms $/ \mathrm{cm}^{2}$ ), are

$$
\frac{d Y_{n}}{d T}=\sum_{\substack{n^{\prime} \\\left(n^{\prime} \neq n\right)}}\left[\sigma\left(n^{\prime}, n\right) Y_{n}^{\prime}-\sigma\left(n, n^{\prime}\right) Y_{n}\right]
$$

where

${ }^{1}$ M.J. Rhoades-Brown, "An Alternative Injection Scheme for Heavy Ions into RHIC", RHIC-44, (1988).

2 "Conceptual Design of the Relativistic Heavy Ion Collider RHIC", May 1989, BNL 52195.

${ }^{3}$ R. Anholt, W.E. Meyerhof, H. Gould, C. Munger, J. Alonso, P. Thieberger, H.E. Wegner, Phys. Rev. A32, 3302 (1985).

${ }^{4}$ W.E. Meyerhof, R. Anhọlt, X- Y. Xu, Phys. Rev. A35, 1055 (1987). 


$$
\sum_{n} Y_{n}=1
$$

In equation (1) cross sections for $n^{\prime}<n$ are loss cross sections and those for $n^{\prime}>n$ capture cross sections. These latter cross sections will be ignored, along with multiple charge- changing processes that happen simultaneously.

The stripping process between the AGS and RHIC allows great simplification of equation (1). Because the two remaining electrons are in the same shell, it is only necessary to know the one-electron ionization cross section, $\sigma_{K}$ for this shell. Defining $\xi$ as the probability each electron has of surviving on the ion after traversing a foil of thickness $T$ as

$$
\xi=e^{-\sigma_{K} T} \quad,
$$

equation (1) can be solved ${ }^{5}$ to give

$$
Y_{n}=\left[\frac{N !}{n !(N-n) !}\right] \xi^{n}(1-\xi)^{N-n}
$$

where the ion enters the foil with $N$ electrons and leaves with $n$.

We are particularly interested in equations (3) and (4) when $n=0, N=2$. In this case, the thickness $T$ is given by

$$
T=-\frac{1}{\sigma_{K}} \log \left(1-\sqrt{Y_{o}}\right) \text { atoms } / \mathrm{cm}^{2}
$$

Introducing the mass of one atomic mass unit, i.e., $1 \mathrm{~m}_{u}=1.66 \times 10^{-24} \mathrm{~g}$, equation (5) becomes

$$
T=\frac{-1.66 A_{t} \log \left(1-\sqrt{Y_{o}}\right)}{\sigma_{K}} \mathrm{~g} / \mathrm{cm}^{2}
$$

where $\sigma_{K}$ is in barns, and $\mathrm{A}_{t}$ is the target mass number.

${ }^{5}$ V.O. Kostroun, In X-Ray and Atomic Inner-Shell Physics-1982, (A.I.P., New York, 1982), p. 303. 


\section{Stripping Foil Thickness}

The single electron $\mathrm{K}$-shell ionization cross section $\sigma_{K}$ has been parameterized ${ }^{6}$ as,

$$
\sigma_{K}=S\left(Z_{t}, Z_{p}\right)\left(\frac{Z_{t}}{Z_{p}}\right)^{2}+t\left(Z_{t}, Z_{p}\right)\left(\frac{Z_{t}}{Z_{p}}\right)^{2}\left(\frac{\log \gamma^{2}-\beta^{2}}{\beta^{2}}\right),
$$

where $Z_{t}, Z_{p}$ are the target and projectile atomic number, and $S\left(Z_{t}, Z_{p}\right), t\left(Z_{t}, Z_{p}\right)$ are tabulated in Ref. (6). Using equation (7) it is found

Table IA. , K-shell ionization cross section for ${ }^{197} \mathrm{Au}^{77+}$ beams.

\begin{tabular}{ll}
\hline $\begin{array}{c}\text { Foil } \\
\text { Material }\end{array}$ & $\sigma_{K}$ (barns) \\
\hline $\mathrm{Al}$ & $1.26 \times 10^{3}$ \\
$\mathrm{Cu}$ & $5.71 \times 10^{3}$ \\
$\mathrm{Au}$ & $38.9 \times 10^{3}$ \\
\hline
\end{tabular}

Table IB. , K-shell ionization cross section for ${ }^{238} \mathrm{U}^{90+}$ beams.

\begin{tabular}{cc}
\hline $\begin{array}{c}\text { Foil } \\
\text { Material }\end{array}$ & $\sigma_{K}$ (barns) \\
\hline $\mathrm{Al}$ & 910.5 \\
$\mathrm{Cu}$ & $4.14 \times 10^{3}$ \\
$\mathrm{Au}$ & $28.38 \times 10^{3}$ \\
\hline
\end{tabular}

In Figs. (1) and (2) the required foil thickness (in $\mathrm{mg} / \mathrm{cm}^{2}$ ) is plotted as a function of the fraction of fully stripped ions. As reflected through equations (6) and (7), the larger $\mathrm{Z}_{t}$ target is preferred over the lighter foils. The logarithmic behavior of $T$ is clearly seen in Figs. (1) and (2). This behavior suggests that a stripping foil of Au with a $98 \%$ efficiency $\left(40 \mathrm{mg} / \mathrm{cm}^{2}\right)$ is a reasonable choice.

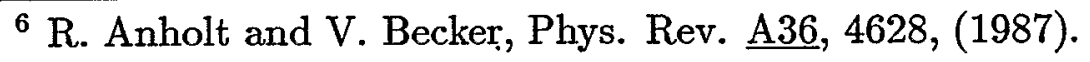




\section{Transverse Emittance Growth in Stripping Foil}

The growth of the transverse emittance from its initial value $\varepsilon_{o}$, due to the beam passing through a stripping foil is

$$
\varepsilon=\varepsilon_{o}+\beta\left\langle\theta^{\mathrm{rms}}\right\rangle^{2}
$$

where $\left\langle\theta^{\mathrm{rms}}\right\rangle$ is the root-mean-square angular spread of the beam after passing through the foil, and $\beta$ is the value of the lattice function where the foil is situated. Following Tsai's article ${ }^{7}$, the quantity $\left\langle\theta^{\mathrm{rms}}\right\rangle$ is given as,

$$
\left\langle\theta^{\mathrm{rms}}\right\rangle=14.98(\mathrm{MeV} / \mathrm{c}) \times \frac{Z_{p}}{p \beta} \sqrt{\frac{T}{X_{o}}}
$$

where $\mathrm{p}$ is the momentum of the projectile, and $\mathrm{X}_{o}$ is a constant that depends on the foil material. From reference (7), $\mathrm{X}_{o}=24.01 \mathrm{~g} / \mathrm{cm}^{2}$ for ${ }^{27} \mathrm{Al}, \mathrm{X}_{o}=12.86 \mathrm{~g} / \mathrm{cm}^{2}$ for ${ }^{63} \mathrm{Cu}, \mathrm{X}_{o}$ $=6.46 \mathrm{~g} / \mathrm{cm}^{2}$ for ${ }^{197} \mathrm{Au}$. Combining equations (6) and (9) for the beam momentum of interest here,

$$
\left\langle\theta^{\mathrm{rms}}\right\rangle^{2}=-3 \times 10^{-6} \frac{Z_{p}^{2} A_{t}}{A_{p}^{2} X_{o} \sigma_{K}} \log \left(1-\sqrt{Y_{o}}\right) \quad \mathrm{rad} .
$$

In Figs. (3) and (4), the quantity $\left\langle\theta^{\text {rms }}\right\rangle^{2}$ is plotted as a function of the fraction of fully stripped ions after the foil. The Au foil produces the smallest angular spread of the foils studied here, however, the differences between the three foils is relatively small.

As an example of the expected emittance growth due to an Au foil of $98 \%$ stripping efficiency ( $40 \mathrm{mg} / \mathrm{cm}^{2}$ ), a lattice function value of $\beta=50 \mathrm{~m}$ corresponds to an emittance change $\varepsilon-\varepsilon_{o}=0.09 \mathrm{~mm} \cdot \mathrm{mrad}$.

\section{Energy Loss and Energy Spread in the Beam due to Passage Through Foil}

The maximum energy spread in the beam after the AGS is $\Delta E=1.0 \mathrm{MeV} / \mathrm{u}$. On passing through the foil between AGS and RHIC, the beam will lose kinetic energy, and the energy spread in the beam will increase.

The energy loss for an ion beam in matter has been tabulated ${ }^{8}$ for beam energies up to $1.0 \mathrm{GeV} / \mathrm{u}$. These tables are extrapolations of a theory that fits the measured data at lower energies (At Berkeley, measurements have been carried out up to $800 \mathrm{MeV} / \mathrm{u}$

${ }^{7}$ Y.-S. Tsai, Rev. of Mod. Phys. 46, 815 (1974).

${ }^{8}$ J.F. Ziegler, The Stopping Powers and Ranges of Ions in Matter, Vol. $\underline{5}$. 
for $\mathrm{Au}$ ions). The energy loss estimates for a beam of energy $10.4 \mathrm{GeV} / \mathrm{u}$ requires an extrapolation of the tabulated losses by more than an order of magnitude. Noting that the energy loss of the beam for a given foil thickness is a monotonically decreasing function of the beam energy ${ }^{8}$, it is assumed here that the value of the gradient, Beam Energy Loss/Beam Energy, between $100 \mathrm{MeV} / \mathrm{u}$ and $1.0 \mathrm{GeV} / \mathrm{u}$ can also be used to extrapolate through the domain $1.0 \mathrm{GeV} / \mathrm{u}$ to $10.0 \mathrm{GeV} / \mathrm{u}$. Using this extrapolation, the following values for the beam energy loss result. ${ }^{8}$

Table IIA. Energy Loss of a $10.4 \mathrm{GeV} / \mathrm{u} \mathrm{Au}^{77+}$ beam in a $98 \%$ efficient Stripping Foil

\begin{tabular}{lc}
\hline $\begin{array}{c}\text { Foil } \\
\text { Material }\end{array}$ & $\begin{array}{c}\text { Beam Energy } \\
\text { Loss } \mathrm{MeV} / \mathrm{u}\end{array}$ \\
\hline${ }^{27} \mathrm{Al}$ & 3.6 \\
${ }^{63} \mathrm{Cu}$ & 1.64 \\
${ }^{197} \mathrm{Au}$ & .65 \\
\hline
\end{tabular}

Table IIB. Energy Loss of a $10.4 \mathrm{GeV} / \mathrm{u} \mathrm{U}^{90+}$ beam in a $98 \%$ efficient Stripping Foil

\begin{tabular}{lc}
\hline $\begin{array}{c}\text { Foil } \\
\text { Material }\end{array}$ & $\begin{array}{c}\text { Beam Energy } \\
\text { Loss } \mathrm{MeV} / \mathrm{u}\end{array}$ \\
\hline${ }^{27} \mathrm{Al}$ & 7.0 \\
${ }^{63} \mathrm{Cu}$ & 2.9 \\
${ }^{197} \mathrm{Au}$ & 1.0 \\
\hline
\end{tabular}

The root-mean-square value of the energy spread before passing through the foil is $\sigma_{E}=1.0 \mathrm{MeV} / \mathrm{u} / \sqrt{6}=0.408 \mathrm{MeV} / \mathrm{u}$. The role of thumb used here are to calculate the additional root-mean-square value of the energy spread after passing through the foil is, $\sigma_{S}=0.1 \times$ beam energy loss in the foil. This is considered extremely conservative by the Tandem people. ${ }^{9}$ Utilizing the quadrature rule and multipling the result by $\sqrt{6}$, the following maximum value of the beam spread results:

${ }^{9} \mathrm{H}$. Wegner, private communication. 
Table IIIA. Maximum Energy Spread of $10.4 \mathrm{GeV} / \mathrm{u} \mathrm{Au}^{79+}$ beam after Stripping Foil

\begin{tabular}{ll}
\hline $\begin{array}{c}\text { Foil } \\
\text { Material }\end{array}$ & $\begin{array}{c}\text { Beam Energy } \\
\text { Spread } \mathrm{MeV} / \mathrm{u}\end{array}$ \\
\hline${ }^{27} \mathrm{Al}$ & 1.33 \\
${ }^{63} \mathrm{Cu}$ & 1.08 \\
${ }^{197} \mathrm{Au}$ & 1.01 \\
\hline
\end{tabular}

Table IIIB. Maximum Energy Spread of $10.4 \mathrm{GeV} / \mathrm{u} \mathrm{U}^{92+}$ beam after Stripping Foil

\begin{tabular}{ll}
\hline $\begin{array}{c}\text { Foil } \\
\text { Material }\end{array}$ & $\begin{array}{l}\text { Beam Energy } \\
\text { Spread MeV/u }\end{array}$ \\
\hline${ }^{27} \mathrm{Al}$ & 1.98 \\
${ }^{63} \mathrm{Cu}$ & 1.23 \\
${ }^{197} \mathrm{Au}$ & 1.03 \\
\hline
\end{tabular}

\section{Discussion}

The calculations presented here indicate that either a ${ }^{63} \mathrm{Cu}$ foil of thickness $\sim 80$ $\mathrm{mg} / \mathrm{cm}^{2}$ or a ${ }^{197} \mathrm{Au}$ foil of thickness $\sim 40 \mathrm{mg} / \mathrm{cm}^{2}$ between the AGS and RHIC would be adequate to fully strip $\mathrm{K}$-shell electrons from $\mathrm{Au}^{77+}$ or $\mathrm{U}^{90+}$ ions. The values obtained for the beam transverse emittance growth in the foil suggest that the precise location of this foil is not a critical factor for injection into RHIC. Additionally, the energy loss of the beam appears negligible $(\sim .01 \%)$ and the energy spread of the beam for ${ }^{63} \mathrm{Cu}$ or ${ }^{197} \mathrm{Au}$ foils also appears to be of no concern for RHIC. 


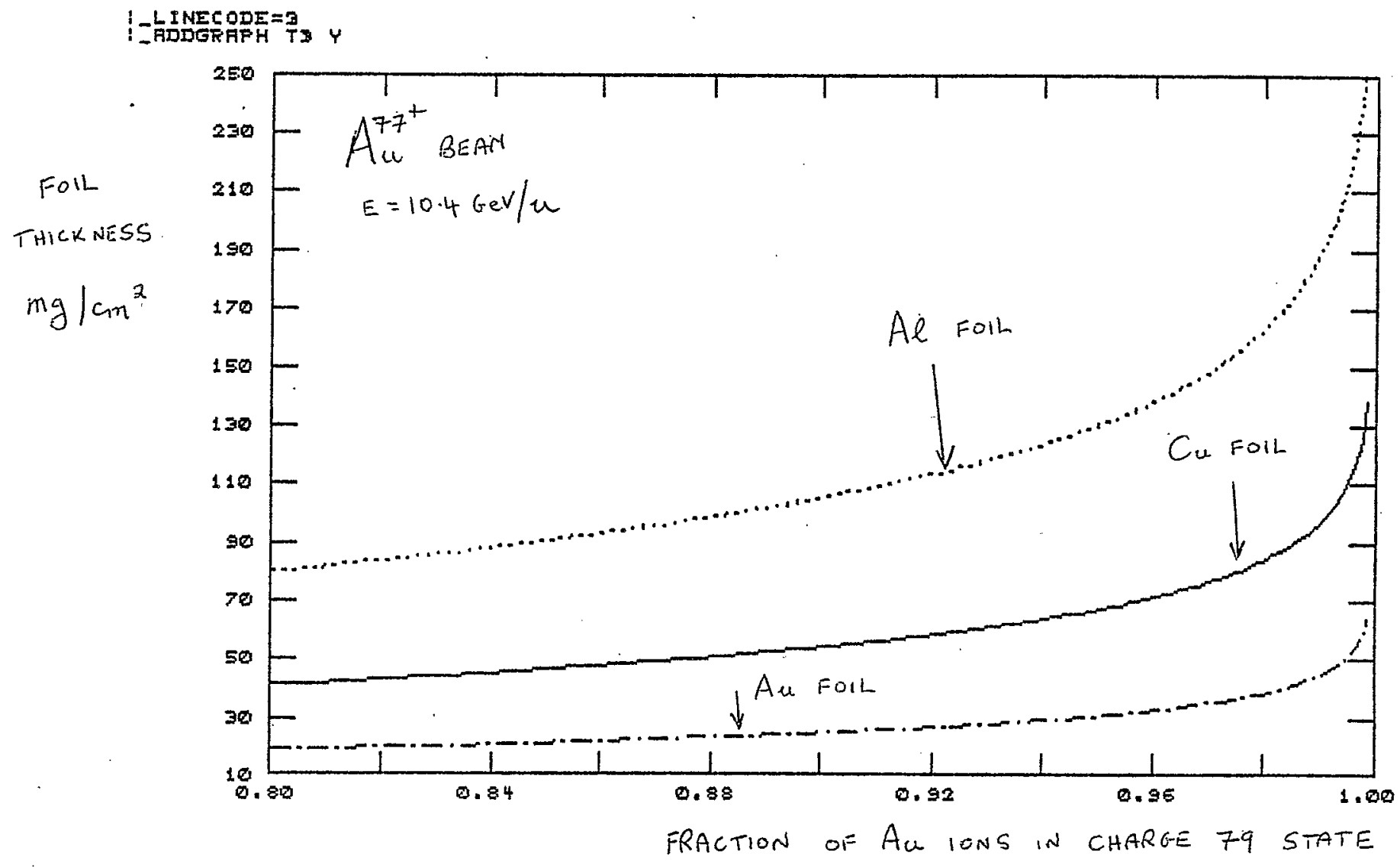

Fig. 1 Plot of the required foil thickness as a fraction of fully stripped $\mathrm{Au}$ ions for $\mathrm{Al}, \mathrm{Cu}$ and Au foils. 


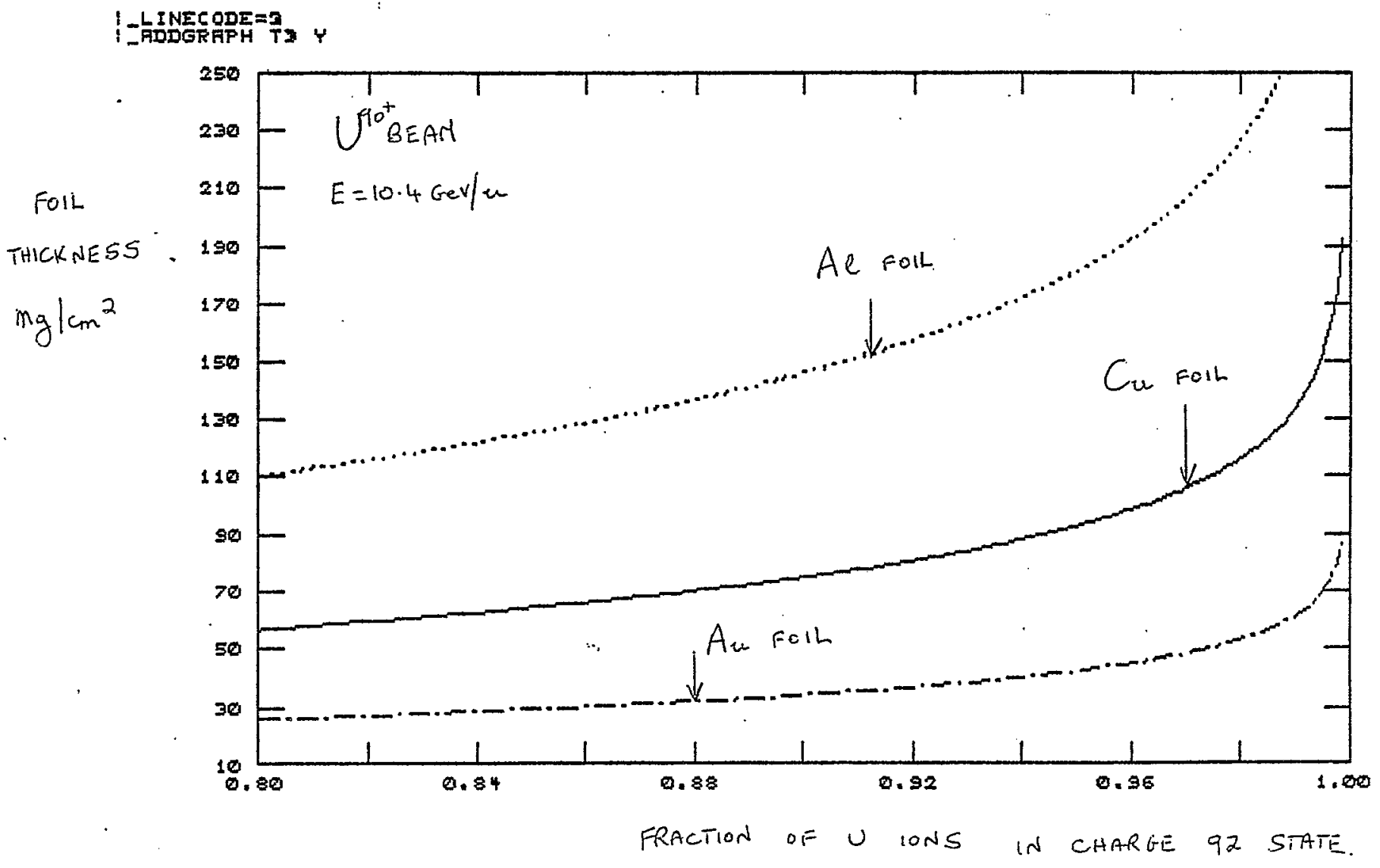

Fig. 2 Plot of the required foil thickness as a fraction of fully stripped $\mathrm{U}$ ions for $\mathrm{Al}, \mathrm{Cu}$ and $\mathrm{Au}$ foils. 


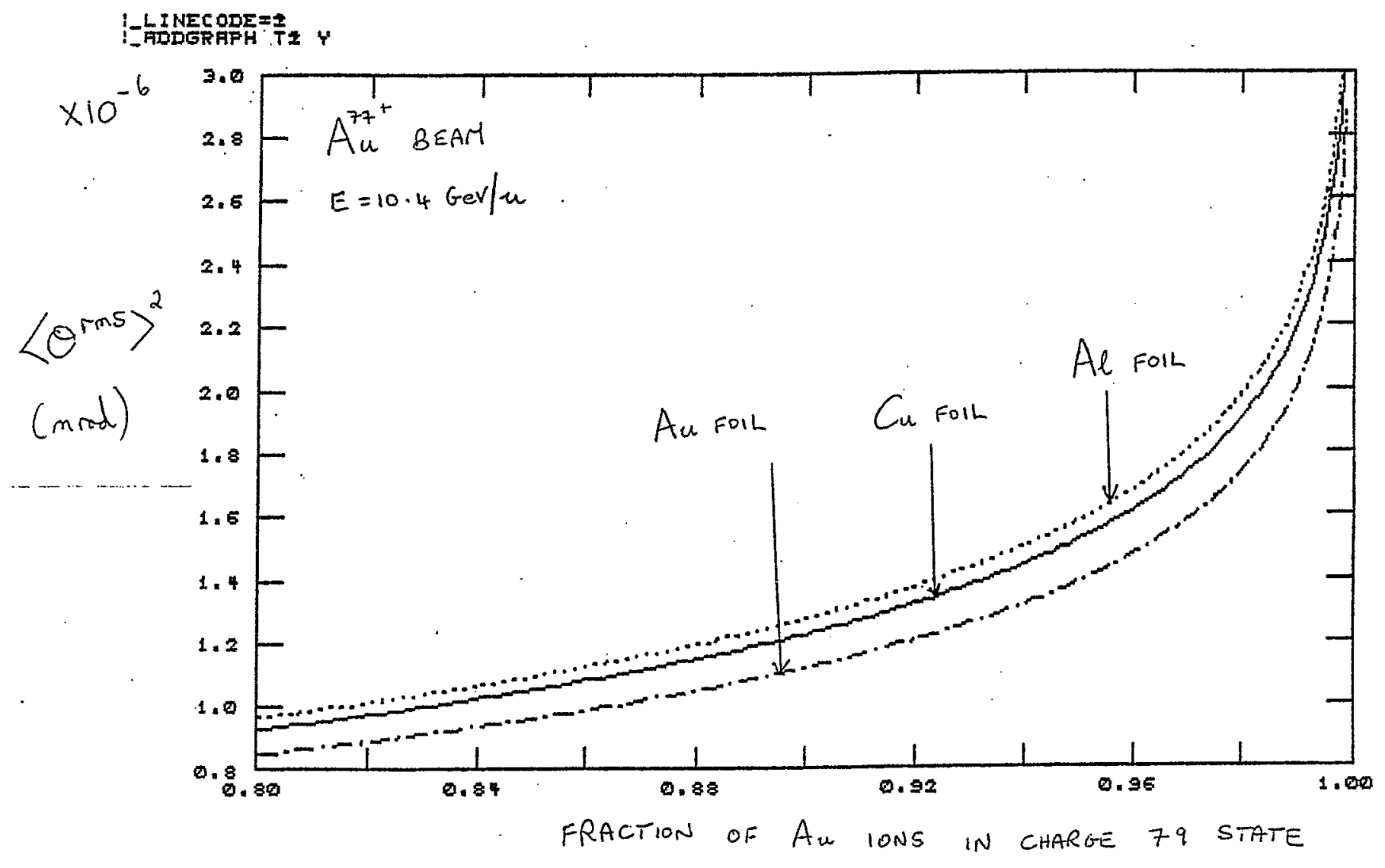

Fig. 3 Plot of the angular spread $\left(\theta^{r m s}\right)^{2}$ as a fraction of fully stripped $\mathrm{Au}$ ions for $\mathrm{Al}, \mathrm{Cu}$ and $\mathrm{Au}$ foils. 


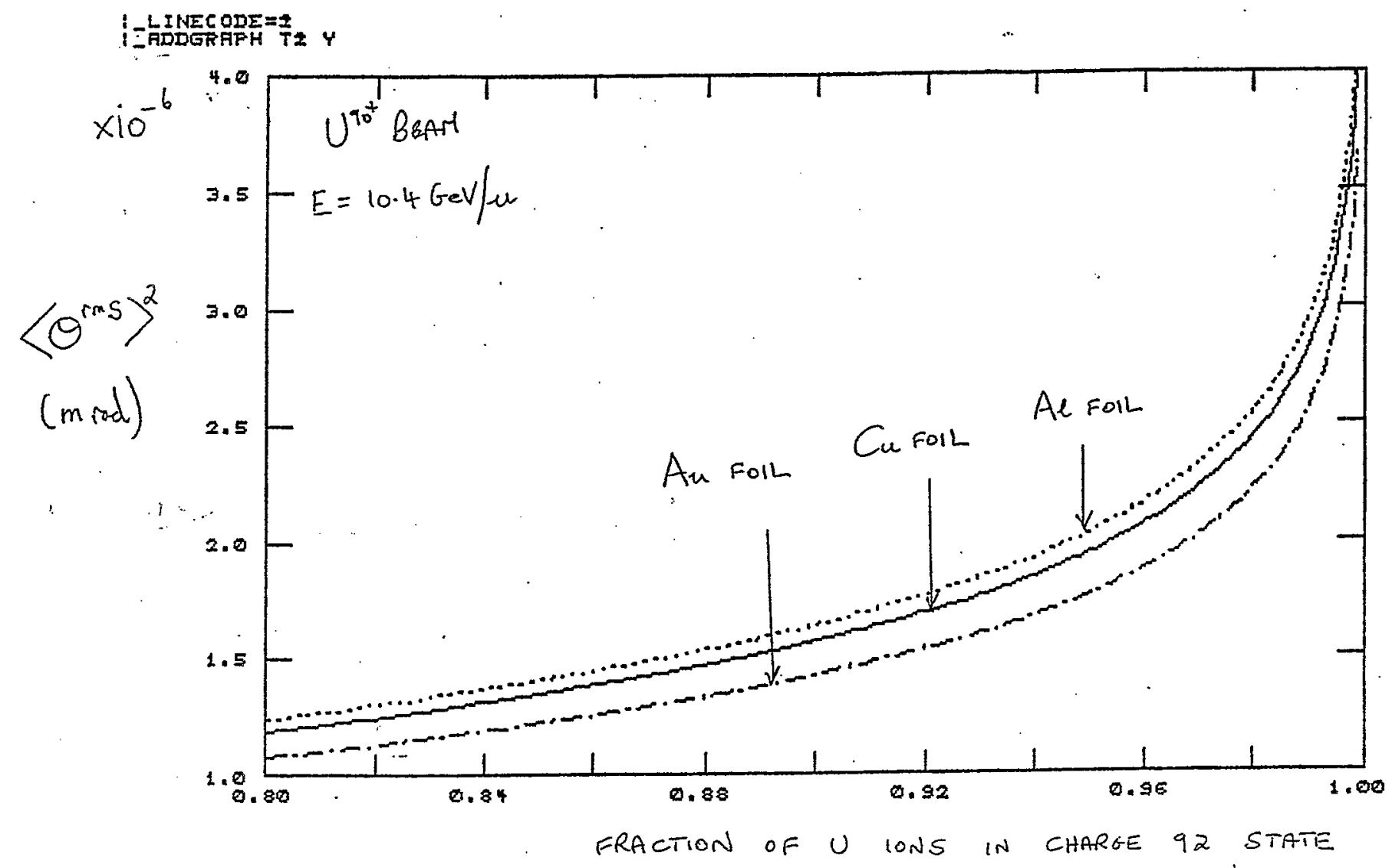

Fig. 4 Plot of the angular spread $\left(\theta^{r m s}\right)^{2}$ as a fraction of fully stripped $\mathrm{U}$ ions for $\mathrm{Al}, \mathrm{Cu}$ and Au foils. 